\title{
Relationship of Antral Follicle Count, Plasma Estradiol and Progesterone Levels with Super Ovulatory Response and Embryo Production in Sahiwal Cows
}

\author{
Nidha Imtiyaz*, Parkash Singh Brar, Narinder Singh, Harpreet Singh, \\ Sumit Singhal and V. S. Malik
}

Department of Veterinary Gynaecology \& Obstetrics, GADVASU, Ludhiana, India

*Corresponding author

Key w o r d s
Antral follicle
count, embryo
production,
estradiol,
progesterone,
Sahiwal

\section{Introduction}

The production and reproduction potential of dairy cows is going to be severely affected due to global warming. Therefore, dairy cows having potential to produce milk at higher environmental temperature are required to mitigate effect of global warming. Sahiwal is considered as the best milch breed of

\begin{abstract}
The study was designed to find correlation between antral follicle count (AFC), plasma levels of estradiol and progesterone with superovulatory response and embryo production in Sahiwal cows. Pluriparous Sahiwal cows $(\mathrm{n}=12)$ were administered estradiol-17 $\beta$ (2 mg, i.m.) along with intravaginal placement of progesterone implant (TRIU-B) at random day of the estrous cycle (day 0). On day 4, cows were administered Folltropin-V @ 100 or 200 mg of NIH FSH PI, divided in 8 tapering doses administered at 12 hourly intervals. PGF2 $\alpha$ was given on day 6 and day 6.5; Implant TRIU-B was withdrawn with last FSH injection. Cows were fixed timed inseminated at 24 and 36 hours of last FSH dose. Results showed that the AFC at start of FSH administration (Day 4) had high positive and significant correlation with superovulatory response $(r=0.863, p=0.0003)$. Mean plasma estradiol was non significantly higher on day of estrus (Day 8) compared to the day of start of FSH treatment (Day 4) and day of embryo collection $(21.8 \pm 3.27,26.4 \pm 3.32$ and $21.6 \pm 2.99 \mathrm{pg} / \mathrm{ml}$, respectively). The number of anovulatory follicles $(>10 \mathrm{~mm})$ present on the day of embryo collection had negative and significant correlation with number of transferable embryo $(\mathrm{r}=-0.609 ; \mathrm{P}=0.0355)$. Plasma progesterone had a weak negative correlation with $>10 \mathrm{~mm}$ follicles $(\mathrm{r}=-0.311, \mathrm{P}>0.05)$ on day of estrus and a weak positive correlation with superovulatory response on the day of embryo collection $(r=0.332, \mathrm{P}>0.05)$. In conclusion, the study indicated that antral follicle count on the day of ovarian stimulation could be used to predict superovulatory response and persistence of anovulatory follicles till the day of embryo collection had adverse effect on embryo quality in Sahiwal cows.

A B S T R A C T
\end{abstract}

indigenous cattle. These cows are better adapted to tolerate high temperatures prevailing in tropical climate due to higher number of sweat glands (Khan et al., 2008). However, population of Sahiwal cows has decreased to a drastic level due to adoption of cross breeding programs. Therefore, efforts are required to improve and propagate this breed at farmer level. 
The reproductive biotechniques like multiple ovulation \& embryo transfer (MOET) could play an important role in faster dissemination of available superior Sahiwal germplasm. However, success of any embryo transfer program depends on successful induction of superovulatory response in selected donor cows which is quite variable and unpredictable.

Numerous intrinsic and extrinsic factors viz. physiological stage of donor animal, breed, nutritional status, type of gonadotrophin used, dose, season, farm management etc. effect superovulatory response in cattle. In addition, antral follicles count (AFC) at the beginning of FSH treatment, circulatory plasma levels of ovarian hormones viz. Estradiol (E2) and Progesterone (P4) play an important role in determining superovulatory response as well as production of transferable embryos. Antral follicle count (AFC) at a given point of time reflects the ovarian follicular reserve and has been positively correlated with superovulatory response and embryo production in the donor cows (Ireland et al., 2008 and Santos et al., 2016). Similarly, a positive significant correlation between concentrations of circulating ovarian steroids at the start of stimulatory treatment and at estrus with number of ovulations has been reported in crossbred cows (Arosh et al., 2001). However, similar information on Sahiwal cows is scanty. Therefore, the present study was undertaken to evaluate relationship between antral follicle count, plasma estradiol and progesterone concentrations with superovulatory response and embryo quality in Sahiwal cows.

\section{Materials and Methods}

\section{Experimental animals}

The study was conducted on pluriparous Sahiwal cows $(n=12)$, non-pregnant, normally cyclic, weighing between 370 to $450 \mathrm{~kg}$ having body condition score (BCS) $>3$ on scale of 5 , maintained at Dairy farm, DLF, Guru Angad Dev Veterinary and Animal Sciences University (GADVASU), Ludhiana. The selected cows were maintained under loose housing and fed with chaffed green fodder, concentrates, wheat straw, mineral mixture, common salt and ad libitum drinking water.

\section{Superstimulatory treatment}

The cows were administered $2 \mathrm{mg}$ of Estradiol-17 $\beta+50 \mathrm{mg}$ of progesterone (Sigma Aldriche, India) along intravaginal Progesterone implant; TRIU-B having 958 mg of progesterone (Virbac Animal Health India Pvt. Ltd., India) on the random day of estrous cycle (Day 0). On Day 4, Follicle stimulating hormone; Folltropin-V @100 or $200 \mathrm{mg}$ NIH-FSH-P1, divided in 8 tapering was administered at 12 hourly intervals for 4 days. Cloprostenol, Inj. Estrumate - Intervet India Pvt. Ltd.; a PGF2 $\alpha$ analogue @ $500 \mu \mathrm{g}$ per cow was injected on day $6^{\text {th }}$ and 6.5. Intravaginal progesterone implant; TRIU-B was removed at the time of last FSH injection. Luitenizing hormone; (Lutropin $12.5 \mathrm{mg}$ Bioniche Animal Health, Inc., Belleville, On, Canada) was given at 12 hours after the last FSH Injection. Cows were inseminated twice i.e. at 24 and 36 hour after last FSH injection using frozen thawed semen of high fertility Sahiwal bulls.

\section{Ultrasonography}

Trans-rectal ultrasonography was performed using ultrasound scanner (Exago, ECM, France) equipped with B- mode linear array transrectal probe using 7.5 $\mathrm{MHz}$ frequency to record the size, location, number of the follicles and corpus luteum (CL). Disappearance of a large follicle $(>10 \mathrm{~mm})$ of previous day scan was considered as 
ovulation. The superovulatory response was determined by counting number of corpora lutea (CLs) on the day of embryo collection i.e. Day 15 of the protocol.

\section{Embryo collection and evaluation}

Embryos collection was done non-surgically on day 15 of the protocol (Day 7 post AI) by two way Worrlein catheter (Minitub $\mathrm{GmbH}$, Germany) with Dulbecoo's phosphate buffered saline supplemented with bovine serum albumin (BSA, 0.1 percent) and Gentamicin@50 $\mu \mathrm{g} / \mathrm{ml}$. Ova/embryos were searched under stereomicroscope and recovered embryos were graded according to the criteria proposed by Robertson and Nelson (1998).

\section{Blood sampling and hormone assay}

Blood samples were collected from jugular vein in heparinised vials on day $0,4,6,8$ and Day 15 of the protocol. Following centrifugation of blood at 2000 RPM for 15 minutes, plasma was collected and stored frozen at $-80^{\circ} \mathrm{C}$ until assay. Plasma estradiol was estimated using a commercially available direct immune enzymatic assay kit (Bovine Estradiol (E2) ELISA Kit), manufactured by Shanghai Yehua Biological Technology Co., Ltd., China. Cat. No: YHB0065Bo. Plasma progesterone was measured using enzyme immunoassay Bovine Progesterone (PROG) ELISA kit, manufactured by Genxbio Health Sciences Pvt. Ltd, China. Cat.No:GXBB01297.

\section{Statistical analysis}

The data was analyzed for means and standard errors (SE) for all variables. After confirming the normality of data and homogeneity of variance, Student's t test (two tailed) was applied to compare mean values of variables.
The relationship of AFC, Plasma estradiol and progesterone with different embryo production parameters was evaluated by Pearson's correlation coefficient. Probability values $<0.05$ were considered significant.

\section{Results and Discussion}

\section{Antral follicle count and embryo production}

Results of the study showed that the number of antral follicles measuring 3 to $5 \mathrm{~mm}$ on the ovaries of donor cows at the time of start of super stimulatory treatment ranged from 13 to 40; and the mean was $23.08 \pm 2.26$ follicles per cow. The AFC at the time of start of FSH administration (i.e. Day 4) had high positive and significant correlation with the superovulatory response $(\mathrm{r}=0.863, \mathrm{p}=$ 0.0003 ) indicating that cows having higher AFC at the start of FSH developed more number of CLs. A positive but very low correlation of AFC was observed with number of embryos recovered and transferable embryos $(\mathrm{r} 1=0.192, \mathrm{r} 2=0.122$; p1 \& p2 >0.05). Various factors like ovulation rate, size of superstimulated ovaries, nutritional status, individual animal variations etc. could be attributed for the non-translation of high correlation observed between AFC and superovulatory response into total and number of transferable embryos recovered. Variable and unpredictable superovulatory response is one of the major impediments in application of embryo transfer technology at farmer level. Some donor cows consistently produce large number of embryos while the others despite similar age, weight, breed, management etc. produce very low or no embryos. The difference in ovarian activity at the time of FSH treatment has been attributed as one of the major reason for such type of variation in superovulatory response (Rico et al., 2009). Singh et al., (2004) reported that AFC was highly variable between individuals 
but highly repeatable between different follicular waves of the same animal in cattle. Various studies had shown that AFC was associated with superovulatory response, indicating reliability of AFC in assessing number of functional follicles that can respond to exogenous FSH treatments, in cattle and humans (Singh et al., 2004 and Hendriks et al., 2005). The objective of exogenous gonadotrophin hormones (FSH or PMSG) is to support small antral follicles to grow and mature and undergo ovulation, resulting in multiple ovulations. Therefore, superovulatory response of a donor should depend on pool of small antral follicles present at the time of initiation of stimulation. In previous studies using ultrasound to determine antral follicle count, Ireland et al., (2007) reported that cows with high follicle numbers had more embryos recovered and had more transferable embryos. Whereas, donor cows with few growing antral follicles had a low ovulatory response and low number of recovered embryos (Kanitz et al., 2002). Our study corroborated the findings that evaluation of AMC (3 to $5 \mathrm{~mm}$ follicles) on the ovaries at time of initiation of superovulatory treatment could be used as an alternate to predictor of superovulatory response in Sahiwal cows. AFC based prediction of superovulatory response for selecting donor could be a more practical approach as many practitioners use ultrasound machines for embryo transfer work.

\section{Plasma estradiol, anovulatory follicles and embryo production}

The results of present study showed that the mean estradiol plasma concentration on Day 4,8 and 15 was $21.8 \pm 3.27,26.4 \pm 3.32$ and $21.6 \pm 2.99 \mathrm{pg} / \mathrm{ml}$, respectively. Although, the mean estradiol plasma concentration was higher on day of estrus (Day 8) compared to day of start of FSH treatment (Day 4) and day of embryo collection (Day 15), the differences were non-significant $(\mathrm{P}>0.05)$. The number of anovulatory follicles $(>10 \mathrm{~mm})$ present on day of embryo collection had negative but significant correlation with number of transferable embryo recovered $(\mathrm{r}=-0.609 ; \mathrm{P}$ $=0.0355)$. Based on the presence of number of anovulatory follicles measuring $>10 \mathrm{~mm}$ on the day of embryo collection; cows were grouped into two groups i.e. Cows having no anovulatory follicle $(>10 \mathrm{~mm}$ follicles $\leq 2)$ and cows having anovulatory follicles (>10 $\mathrm{mm}$ follicles >2) as shown in Table-3.

Out of the twelve superovulated Sahiwal cows, five cows showed $>2$ anovulatory follicles on the day of embryo collection and seven cows had $\leq 2$ follicles measuring on the day of embryo collection. Based on number of anovulatory follicles present on Day 15, the difference was significant between the two groups $(\mathrm{P}<0.001)$

No significant difference in AFC at the start of FSH treatment (Day 4) and at the time of estrus (Day 8) were observed between the cows having $\leq 2$ vs. $>2$ anovulatory follicles. The mean number of CLs and embryos recovered were comparatively lower in Sahiwal cows having $>2$ anovulatory follicles compared to cows having $\leq 2$ anovulatory group $(15.4 \pm 2.87 \& 7.6 \pm 3.04$ vs. $16.6 \pm 2.40 \&$ $11.4 \pm 3.44$, respectively. Although the difference was statistically non-significant but the cows having $\leq 2$ yielded more number of transferable embryos compared to cows having $>2$ anovulatory follicles $(4.9 \pm 1.56$ vs. $1.4 \pm 0.75$, respectively). Plasma estradiol levels at the start of FSH treatment (Day 4) and on the day of estrus (Day 8) were higher in Sahiwal cows having $\leq 2$ anovulatory follicles compared to cows having $>2$ anovulatory follicles; the difference tended to be significant on Day 4 (26.9 \pm 4.65 vs. 15.4 $\pm 2.80 \mathrm{pg} / \mathrm{ml}$, respectively, $\mathrm{P}=0.09)$ and numerically higher on Day $8(29.7 \pm 5.19$ vs. $21.9 \pm 2.7 \mathrm{pg} / \mathrm{ml}$, respectively, $\mathrm{P}=0.267$ ). 
Table.1 Antral follicle count (AFC), superovulatory response and embryo production parameters in Sahiwal cows

\begin{tabular}{|c|c|c|c|}
\hline Sr. No. & Parameter & Mean Values \pm SE & Range \\
\hline $\mathbf{1}$ & $\begin{array}{c}\text { No. of Follicles 3- 5 mm - Day 4 } \\
\text { (Start of FSH Administration) }\end{array}$ & $23.08 \pm 2.26$ & $13-40$ \\
\hline $\mathbf{2}$ & $\begin{array}{c}\text { No. of Ovulatory Follicles (>10 mm) - Day 8 } \\
\text { (Day of Estrus \& AI) }\end{array}$ & $28.58 \pm 2.97$ & $0-7$ \\
\hline $\mathbf{3}$ & $\begin{array}{c}\text { Anovulatory Follicles (>10 mm) - Day 15 } \\
\text { (Day of Embryo Collection) }\end{array}$ & $2.67 \pm 0.80$ & $9-28$ \\
\hline $\mathbf{4}$ & $\begin{array}{c}\text { Superovulatory Response (CLs) - Day 15 } \\
\text { (Day of Embryo Collection) }\end{array}$ & $16.08 \pm 1.76$ & $0-28$ \\
\hline $\mathbf{5}$ & Embryos recovered & $9.83 \pm 2.34$ & $0-10$ \\
\hline $\mathbf{6}$ & Transferable embryos & $3.42 \pm 1.06$ & $0-16$ \\
\hline
\end{tabular}

Table.2 Correlation of Antral follicle count and anovulatory follicles with different embryo production parameters in Sahiwal cows

\begin{tabular}{|c|c|l|c|c|}
\hline Sr. No. & Variable 1 & Variable 2 & $\begin{array}{c}\text { Correlation } \\
\text { Coefficient }\end{array}$ & P-values \\
\hline A & Antral follicle count & Superovulatory response & 0.863 & $\mathbf{0 . 0 0 0 3}$ \\
\hline & $(3-5 \mathrm{~mm})$ & Embryo recovery & 0.192 & 0.5499 \\
\hline \multirow{2}{*}{ B } & Day 4 & Transferable embryo & 0.122 & 0.7056 \\
\hline & Anovulatory Follicles & Superovulatory response & -0.052 & 0.8724 \\
\cline { 2 - 5 } & $(>10 \mathrm{~mm})$ & Embryo recovery & -0.124 & 0.7010 \\
\hline & Day 15 & Transferable embryo & -0.609 & $\mathbf{0 . 0 3 5 5}$ \\
\hline
\end{tabular}

Table.3 Effect of Anovulatory follicles on embryo production and plasma estradiol in Sahiwal cows

\begin{tabular}{|c|c|c|c|c|}
\hline $\begin{array}{l}\text { Sr. } \\
\text { No. }\end{array}$ & Parameter & $\begin{array}{l}\text { No Anovulatory } \\
\text { follicle Cows } \\
(n=7)\end{array}$ & $\begin{array}{l}\text { Anovulatory follicle } \\
\text { Cows } \\
(n=5)\end{array}$ & $\begin{array}{c}\text { P-values } \\
\text { (T Test) }\end{array}$ \\
\hline $\mathbf{1}$ & Total follicles Day 4 & $23.8 \pm 20.2$ & $22.6 \pm 13.3$ & 0.867 \\
\hline 2 & Total follicles Day 8 & $28.2 \pm 26.4$ & $26.4 \pm 15.4$ & 0.560 \\
\hline 3 & $\begin{array}{c}\text { Follicles }>10 \mathrm{~mm} \\
\text { Day } 15\end{array}$ & $0.6 \pm 0.6^{*}$ & $5.6 \pm 3.2 *$ & 0.000 \\
\hline 4 & $\begin{array}{l}\text { Superovulatory Response } \\
\text { (CLs) Day } 15\end{array}$ & $17 \pm 14.3$ & $15.4 \pm 9.0$ & 0.760 \\
\hline 5 & Embryos Recovered & $13.8 \pm 9.9$ & $7.6 \pm 4.9$ & 0.447 \\
\hline 6 & Viable embryos & $4.8 \pm 4.3$ & $1.4 \pm 0.95$ & 0.111 \\
\hline \multirow[t]{4}{*}{7} & Plasma Estradiol & & & \\
\hline & Day 4 & $26.86 \pm 22.9$ & $15.36 \pm 8.99$ & 0.099 \\
\hline & Day 8 & $29.74 \pm 25.9$ & $21.9 \pm 12.7$ & 0.267 \\
\hline & Day 15 & $19.86 \pm 19.2$ & $21.9 \pm 12.8$ & 0.948 \\
\hline
\end{tabular}

Values marked with superscript $(*)$ in a same row differ significantly at $1 \%$ level 
On Day 15, similar values of plasma estradiol were recorded in Sahiwal cows having $\leq 2$ anovulatory follicles and $>2$ anovulatory follicles $(19.86 \pm 4.55$ vs 21.9 \pm 3.91 , respectively) indicating that the presence of higher number of anovulatory follicles did not contributed much to plasma estradiol level.

\section{Plasma progesterone and embryo production}

The mean plasma progesterone concentrations on Day $0,4,6,8$ and 15 were $1.78 \pm 0.10$, $2.17 \pm 0.27, \quad 2.37 \pm 0.16, \quad 0.68 \pm 0.05 \quad$ and $2.73 \pm 0.11$, respectively. Although, the mean plasma progesterone concentrations observed on Day 4 were higher than Day 0 but the difference was non-significant. The plasma progesterone concentrations were significantly higher on Day 6 compared to Day 0 (2.37 \pm 0.16 vs. $1.78 \pm 0.10$, respectively; $\mathrm{P}<0.05)$ but not than Day 4 of the protocol.

On the day of estrus (Day 8), plasma progesterone concentrations were significantly lower as compared to the other days under the study. Highest plasma progesterone concentrations were observed on day of embryo collection (Day 15) which was significantly higher than the day of estrus $(2.73 \pm 0.11$ vs. $0.68 \pm 0.05$, respectively; $\mathrm{P}$ $<0.05)$. A weak negative correlation $(\mathrm{r}=$ $0.311, \mathrm{P}>0.05$ ) was observed between plasma concentration on day of estrus (Day 8) and ovulatory sized follicles (>10 mm follicles) whereas, a positive but weak correlation $(\mathrm{r}=$ $0.332, \mathrm{P}>0.05)$ was recorded between plasma progesterone concentration on day of embryo collection and superovulatory response. The mean progesterone concentrations on the day of estrus and embryo collection observed in the present study were lower than in the Ongole cows $(2.3 \pm 0.3$ and $9.6 \pm 3.15 \mathrm{ng} / \mathrm{ml})$ reported by Duddukuri (2015). Mutha Rao et al., (2005) and Siddiqui et al., (2011) also reported similar pattern of increase in concentrations of progesterone from day of estrus to day of embryo collection. Goto et al., (1988) reported that higher levels of $\mathrm{P} 4$ on the first treatment day resulted in significant higher superovulatory response, total embryos and viable embryos. However, the present study did not find any relationship between P4 concentration on the day of treatment and ovarian response. This was in agreement with earlier reports of Walton and Stubbings (1986) and Lopes et al., (2001).

Wiley et al., (2019) reported that the start of superstimulatory treatment during low level of endogenous progesterone due to regressing CL could decrease the overall embryo production. Number of transferable embryos recovered in the present study was comparatively low compared to superovulatory response and total embryo recovery which warrants further investigation. Brar and Nanda (2008) reported that better management practices, housing, nutrition supplemented with minerals and vitamins had shown to improve reproductive performance of Bos indicus cows. The results of the present study showed that antral follicle count on the day of ovarian stimulation could be used to predict superovulatory response and persistence of anovulatory follicles till the day of embryo collection had adverse effect on embryo quality in Sahiwal cows.

\section{Acknowledgements}

The authors thank Guru Angad Dev Veterinary and Animal Sciences University, Ludhiana, Punjab, India for the financial assistance under the RKVY project.

\section{Compliance with ethical standards}

The presented research was conducted in accordance with the ethical standards of Guru Angad Dev Veterinary and Animal Sciences University, Ludhiana, Punjab, India. 


\section{References}

Arosh, J. A., Banu, K. S., Devanathan, T. G. and Kathiresan, D. 2001. The pattern of superoestrus and its influence on ovarian response, embryo recovery and quality of embryos in prostaglandin F2 alpha and syncromate B induced superovulated crossbred cows. Indian Journal of Animal Sciences 71: 425-29.

Brar, P. S. and Nanda, A. S. 2008. Postpartum ovarian activity in South Asian Zebu cattle. Reproduction in Domestic Animals 43: (Supp 2) 207-212.

Duddukuri, Yedukondalu 2015. Effect of lower doses of FSH on Superovulatory responses in ongole cattle :M VSc thesis submitted to Sri VenkateswaraVeterinary University, Tirupati.

Goto, K., Ohkutsu, S., Nakanishi, Y., Ogawa, K., Tasaki, M., Ohta, H., Inohae, S., Tateyama, S., Kawabata, T., Ishii, S., Miyamoto, A. 1988. Endocrine profiles and embryo quality in superovulated Japanese Black Cattle. Theriogenology 29: 615-629.

Hendriks, D. J., Mol, B. W. J., Bancsi, L., te Velde, E. R., Broekmans, F. J. M. 2005. Antral follicle count in the prediction of poor ovarian response and pregnancy after in vitro fertilization: a meta-analysis and comparison with basal follicle stimulating hormone level. Fertility and Sterility 83:291-301.

Ireland, J. J., Ward, F., Jimenez-Krassel, F., Ireland, J. L. H., Smith, G. W., Lonargen, P., Evans, A.C.O. 2007. Follicle numbers are highly repeatable within individual animals but are inversely correlated with $\mathrm{FSH}$ concentrations and proportion of good quality embryos after ovarian stimulation in cattle. Human
Reproduction 22: 1687-1695.

Ireland, J. L. H., Scheetz, D., JimenezKrassel, F., Themmen, A. P. N., Ward, F., Lonergan, P., Smith, G. W., Parez, G. I., Evans, A.C.O., and Ireland, J. J. 2008. Antral follicle count reliably predicts number of morphologically healthy oocytes and follicles in ovaries of young adult cattle. Biology of Reproduction 79: 1219-1225.

Kanitz, W., Becker, F., Schneider, F., Kanitz, E., Leiding, C., Nohner, H. P., Pohland, R. 2002. Superovulation in cattle: practical aspects of gonadotropin treatment and insemination. Reproduction Nutrition and Development 42: 587-599.

Khan, M. S., Rehman, Z. U., Khan, M. A. and Ahmad, S. 2008. Genetic resources and diversity in Pakistani cattle. Pakistan Veterinary Journal 28: 95102.

Lopes, dacosta L., Silva, J. C. C. and Silva, J. R. 2001. Superovulatoryresponse, embryo Quality and fertility after treatment with different gonadotrophins in native cattle. Theriogenology 56: 65-77.

Mutha Rao, M., Mahesh, U. Y. and Babu Rao, K. 2005. Peri ovulatory steroid profile in Relation to superovulatory responses in native Ongole cows. The Indian Journal of Animal Reproduction 26: 87-90.

Rico, C., Fabre, S., Medigue, C, Di Clemente, N, Clement, F, Bontoux, M, Touze JL, Dupont, M., Briant, E., Remy, B., Beckers, J.F., and Monniaux, D. 2009. Anti mullerian hormone is an endocrine marker of ovarian gonadotrophin responsive follicles and can help to predict superovulatory response in the cow. Biology of Reproduction 80: 50-59.

Robertson, I. and Nelson, R. E. 1998. Certification and identification of the 
embryo. Manual of the International Embryo Transfer Society (Stringfellow, D.A.; Seidel, S.M.; eds). IETS, Savoy, IL: 103-134.

Santos, G. M. G. D., Silva-Santos, K. C., Barreiros, T. R. R., Morotti F., Sanches, B. V., de Moraes, F. L. Z., Blaschi, W., Seneda, M. M. 2016. High numbers of antral follicles are positively associated with in vitro embryo production but not the conception rate for FTAI in Nelore cattle. Animal Reproduction Science 165:17-21.

Siddiqui, M. U., Panchal, M. T. and Kavani, F. S. 2011. Circulating ovarian steroids in relation to superovulatory response and embryo recovery in Sahiwal cows and heifers. Indian
Journal of Animal Reproduction 32: 12-16.

Singh, J., Dominguez, M., Jaiswal, R., Adams, G. P. 2004. A simple ultrasound test to predict the superstimulatory response in cattle. Theriogenology 62: 227-243

Walton, J. S. and Stubbings, R. B. 1986. Factors affecting the yield of viable embryos by superovulated HolsteinFriesian cows. Theriogenology 26: 167-77.

Wiley, C., Jahnke, M., Redifer, C., Gunn, P. J., Dohlman, T. 2019. Effects of endogenous progesterone during ovarian follicle superstimulation on embryo quality and quantity in beef cows. Theriogenology 129: 54-60.

\section{How to cite this article:}

Nidha Imtiyaz, Parkash Singh Brar, Narinder Singh, Harpreet Singh, Sumit Singhal and V. S. Malik. 2020. Relationship of Antral Follicle Count, Plasma Estradiol and Progesterone Levels with Super Ovulatory Response and Embryo Production in Sahiwal Cows. Int.J.Curr.Microbiol.App.Sci. 9(06): 352-359. doi: https://doi.org/10.20546/ijcmas.2020.906.046 